\title{
As formações imaginárias e seus efeitos de sentido no ensino e na aprendizagem de criação publicitária
}

Fábio Hansen'

\section{Resumo}

A partir das noções de formações imaginárias e antecipação, este artigo apresenta uma reflexão sobre o ensino de criação publicitária na perspectiva teórica da análise de discurso. Examinamos como o mundo profissional insere-se na prática docente e na dinâmica da sala de aula, entrelaçando-se ao discurso pedagógico. Diante disso, o objetivo do estudo foi investigar o modo como a imagem que o professor atribui a si e aos estudantes produz efeitos de sentido nos procedimentos didático-pedagógicos em disciplinas da área de criação publicitária. Para cumprir tal objetivo, recorremos a uma pesquisa de caráter empírico, na qual selecionamos sequências discursivas produzidas em 2011 por meio da gravação em áudio e vídeo de aulas das disciplinas de Criação, Direção de Arte, Redação Publicitária e Criação de Campanha na Escola Superior de Propaganda e Marketing de Porto Alegre. Revelamos que o conteúdo programático trabalhado em sala de aula e que emerge durante a preparação do curso é determinado pelas formulações imaginárias do professor, pela antecipação do efeito de sentido e pela homogeneização dos estudantes. A ação educativa é norteada pela antecipação da resistência do sistema de ensino. Por fim, pode-se afırmar que o lugar de professor e de aluno são representações socialmente incorporadas que impactam terminantemente as práticas pedagógicas.

\section{Palavras-chave}

Ensino - Imaginário - Antecipação - Criação publicitária - Mercado publicitário. 


\title{
Imaginary formations and their meaning effects in the teaching and learning of publicity creation
}

Fábio Hansen'

\begin{abstract}
Based on the notions of imaginary formation and anticipation, this article presents a reflection on the teaching of publicity creation under the theoretical perspective of the discourse analysis. We examine how the professional world is inserted in the teaching practice and in the classroom dynamics, intermingled with the pedagogical discourse. In view of that, the objective of this study was to investigate how the image that the teacher attributes to himself/herself and to the students produces meaning effects in the didactic-pedagogical procedures in disciplines of the area of publicity creation. In order to do that, we conducted an empirical research in which we selected discourse sequences produced in 2010 through audio and video recording of classes in the disciplines of Creation, Art Direction, Publicity Writing and Campaign Creation at the Escola Superior de Propaganda e Marketing (Higher School of Publicity and Marketing) of Porto Alegre. We found out that the program worked in the classroom, and which emerges during the preparation of the course, is determined by the imaginary formulations of the teacher, by the anticipation of the meaning effect, and by the homogenization of students. The educative action is guided by the anticipation of the resistance of the teaching system. Lastly, we discovered that the places of teacher and of student are socially incorporated representations that impact decisively upon pedagogical practices.
\end{abstract}

\section{Keywords}

Teaching - Imaginary - Anticipation - Publicity creation - Publicity market.

I- Universidade Federal do Rio Grande

do Sul, Porto Alegre, RS, Brazil.

Contact: fabiohansen@yahoo.com 
Nos últimos dois anos estamos investigando o ensino de publicidade sob uma perspectiva discursiva. Em nossas pesquisas, refletimos a respeito da relação do ensino de criação publicitária com o mercado publicitário. Em um primeiro texto publicado (HANSEN; NEUMANN; SILVA, 2010), examinamos, apenas a partir de uma pesquisa de caráter teórico com levantamento bibliográfico apoiado em autores brasileiros que repercutem a intersecção da área de comunicação com os ambientes educacional e profissional -, de que modo o processo de ensino e aprendizagem tem sido atravessado pela prática do mercado.

Posteriormente, em 2011, já como desdobramento da pesquisa intitulada $O$ mercado publicitário em sala de aula: um olhar discursivo sobre o ensino de criação publicitária, fınanciada pelo Núcleo de Pesquisas e Publicações da Escola Superior de Propaganda e Marketing Sul (NuPP ESPM Sul), publicamos mais dois textos. Em um deles (HANSEN, 2011a), analisamos, respaldados por pesquisa empírica, as condições de produção do discurso publicitário em sala de aula, comparando-as com as condições em que o discurso publicitário é produzido no mercado publicitário.

No texto seguinte (HANSEN, 2011b), por meio da noção de memória discursiva, avaliamos o consumo dos saberes do mundo do trabalho publicitário em aulas de disciplinas cuja fınalidade é o ensino de criação publicitária. Tanto a pesquisa de caráter teórico quanto a pesquisa empírica serviram-nos de alicerce para ir além. Portanto, este artigo dá seguimento à investigação iniciada e materializada nos textos supracitados e integra a pesquisa desenvolvida junto ao NuPP da ESPM Sul.

Diante dos resultados já obtidos, desenvolvemos a hipótese de que o imaginário do professor sobre o próprio lugar e sobre o lugar do estudante está relacionado com a inclusão do discurso do mercado publicitário no ensino de criação publicitária. Sendo assim, para dar sequência à compreensão das práticas pedagógicas nas disciplinas de criação publicitária, permanecemos abordando o ensino de criação publicitária sob uma perspectiva teórico-empírica. Desta feita, na constituição do dispositivo teórico para respaldar a discussão conceitual, mobilizamos as noções de formações imaginárias e de antecipação relacionadas à análise de discurso francesa.

No que tange à materialidade discursiva utilizada para fins de análise, constituímos a montagem do arquivo discursivo a partir do registro das produções discursivas de professores e alunos de disciplinas da área de criação publicitária da ESPM Sul. Na coleta do corpus, gravamos, em áudio e vídeo, aulas das disciplinas de Criação, Direção de Arte, Redação Publicitária e Criação de Campanha. As sequências discursivas (SDs) oriundas das gravações foram originadas com base nas transcrições do material coletado no segundo semestre de 2011. Tomamos esse material como corpus de análise e dele recortamos as sequências discursivas - a serem apresentadas ao longo do presente texto - em que observamos o imaginário construído sobre o lugar do professor e dos estudantes e sua implicação na inserção do mundo do trabalho publicitário no discurso pedagógico de criação publicitária.

Partimos da premissa de que a imagem que o professor constrói em relação ao seu lugar e ao lugar do estudante impacta os procedimentos didático-pedagógicos. Diante disso, o objetivo das reflexões aqui propostas é investigar como o imaginário do professor sobre si e sobre seu interlocutor produz efeitos de sentido no ensino e na aprendizagem de criação publicitária. Em síntese, importa-nos compreender o modo como professor e estudante são imaginados nesse espaço discursivo e os efeitos produzidos sobre o fazer educativo.

A relevância deste estudo remete à inexpressiva produção de conhecimento científico acerca do ensino de publicidade e propaganda e, sobretudo, do ensino de criação publicitária, embora a criação (de ideias, conceitos, argumentos) seja a essência da atividade publicitária. Acreditamos que a riqueza deste texto, para 
além da fundamentação teórica das noções de formações imaginárias e de antecipação, está em seu caráter empírico. 0 trabalho de campo para observar a prática pedagógica propicia ao professor a reflexão sobre as várias linhas condicionantes de sua aula, entre elas a imagem que atribui a si e aos estudantes e o modo como tais formulações imaginárias que permeiam o fazer educativo interferem nos procedimentos didático-pedagógicos.

\section{O lugar de professor}

Este artigo parte do raciocínio de que o professor necessariamente inclui em sua aula o dizer proveniente do mercado publicitário. Ambos estão interligados: mercado publicitário e ensino de criação publicitária são como unha e carne. 0 mercado publicitário insere-se nos conteúdos e saberes pedagogizados. Sobre esse aspecto parece não restar dúvida. 0 que nos importa é desvendar como - para além do senso comum - isso acontece. Para tanto, contamos com o auxílio da noção de formações imaginárias.

0 imaginário nos encaminha à afırmação de Pêcheux (1993, p. 75) de que "um discurso é sempre pronunciado a partir de condições de produção dadas", sendo estas definidas pelo autor como "as circunstâncias de um discurso". Dentre tais circunstâncias, Pêcheux (1993, p. 82) destaca as formações imaginárias:

0 que funciona nos processos discursivos é uma série de formulações imaginárias que designam o lugar que A e B se atribuem cada um a si e ao outro, a imagem que eles fazem do seu próprio lugar e do lugar do outro.

Transpondo essa proposição ao ensino de criação publicitária, entendemos que A corresponde ao professor e B corresponde ao estudante. A julgar pelas sequências discursivas (SDs) 1 e 2 apresentadas a seguir, a questão elaborada por Pêcheux (1993, p. 82) - "quem sou eu para lhe falar assim?" - repercute no fazer educativo em sala de aula. E é por ela que iniciaremos, analisando a noção de formação imaginária pela imagem que o professor faz de si mesmo.

SD1 - Eu lembro que a gente ganhou uma vez um prêmio de no media.

SD2 - Eu estava falando com um amigo meu que trabalha na W3haus ${ }^{1}$ que atende a Kraft Foods ${ }^{2}$ aqui no Brasil.

Nas sequências discursivas (SDs) recortadas para análise, a palavra prêmio e os nomes da agência e do anunciante vêm de outro lugar do saber (do discurso do mundo profissional) e impõem-se como apropriados ao dizer pedagógico, uma vez que servem para legitimar o saber do professor diante do aluno. Ancorado no discurso do mundo profissional, o professor pode influenciar o aluno a não questionar ou discutir. É o exterior apropriado ao dizer. É o discurso pedagógico constituído em referência às condições externas - nesse caso, o mercado de trabalho e os sentidos de autoridade nele colados.

Todavia, a imagem que o locutor (professor) faz de si mesmo é atravessada pelo mundo profissional. De tal ato, derivam algumas interpretações. A primeira diz respeito a qual eu da pergunta de Pêcheux ("quem sou eu para lhe falar assim?”) estamos nos referindo. 0 eu professor, claro. É a ele que nos referimos. Mas não podemos deixar de nos referir, igualmente, ao eu publicitário da área de criação. Na SD1, é assim que o professor se situa, como profissional de criação vencedor de um prêmio, transferindo ao eu professor a reputação alcançada. Em um ato contínuo, o professor se deixa atravessar pelo discurso do mercado publicitário, uma vez que se vale de sua experiência (SD1) e de seus contatos no mercado publicitário (SD2) para legitimar sua condição de professor da área de criação publicitária. Ao atuar como professor, o publicitário desenvolve a ampliação dos sentidos dados à profıssão, vista como um saber eminentemente técnico.

\footnotetext{
1- Importante agência brasileira de publicidade digital.

$\mathbf{2}$ - Anunciante renomado do mercado mundial.
} 
É como se o professor dissesse: eu sou o professor e preciso materializar tal condição. Para tanto, recorre a uma formulação imaginária (elementar): a de que o mercado publicitário legitima seu dizer. Ao recorrer ao discurso profissional, apregoando sua sabedoria, o professor imagina apoderar-se de credibilidade, afırmando-se. Atuando ou não no mercado publicitário (em agências, anunciantes, veículos, fornecedores etc.), o professor presume que seu dizer terá maior respaldo ao se reportar ao mercado. Essa é uma das formulações imaginárias que funcionam no discurso pedagógico de criação publicitária.

Adotando um tom mais reflexivo, se o professor necessita recorrer ao discurso do mercado (sabemos ser esta uma prática comum em sala de aula, e não estamos aqui para criticá-la, mas para apurá-la) a fim de avalizar seu dizer e denotar domínio da matéria, cabe-nos pensar sobre as circunstâncias desse episódio.

Parece-nos que, ao tentar responder à questão "quem sou eu para lhe falar assim?", não basta ao professor dizer que é professor. Assim, atribuímos uma posição de inferioridade ao ser apenas professor. 0 contraponto é vincular-se de alguma maneira ao mercado publicitário, atuando ativamente ou fazendo menção a ele. Desse modo, sobressai-se o imaginário de uma conotação superior, chancelada por um prêmio conquistado (SD1) ou pela alusão a uma agência criativa (SD2).

Em outros termos, a imagem que o professor faz de seu próprio lugar de professor não lhe parece suficiente para sustentar seu dizer. Nessa hipótese, o professor ocupa e atribui a si um lugar secundário. É como se não lhe bastasse ser professor. Intuímos que o olhar que o professor ${ }^{3}$ tem sobre o lugar de professor não lhe é suficiente para ensinar criação publicitária. Portanto, manifesta-se o eu professor, mas também o eu profissional de criação, instituindo-se representante do

3- Convém recordar que não estamos tratando do sujeito cognitivo, mas sim operando a partir das formulações imaginárias que, para a Análise do Discurso (AD), são da ordem do inconsciente e determinadas sóciohistórica e ideologicamente. mercado publicitário para abordar em aula seu funcionamento.

André Porto Alegre, conselheiro de administração e da diretoria executiva da APP (Associação dos Profissionais de Propaganda), observa:

[...] para um médico ou um advogado é uma honra dar aula, já para o publicitário a realidade é outra: esse é um ponto fraco do ensino que prejudica a cadeia de formação dos novos profissionais. (CENP, 2011, p. 16)

Fundamentados na opinião de Porto Alegre, fortalecemos a impressão de que aquele professor que atua simultaneamente no mercado publicitário não se sente efetivamente professor. Não incorporou a condição de professor. Está professor, mas não é professor. É um criativo atuante no mercado de trabalho. Esta é outra formulação imaginária: o professor (esporádico) que não se vê como professor.

Tal visão, de acordo com Ferreira (s. d.), ainda está muito longe do verdadeiro sentido que se deve dar à expressão tornar-se professor e, por consequência, do papel do professor comprometido com a ação educativa. 0 professor não tem noção da complexidade de ser professor, de estar em sala de aula e do tamanho da responsabilidade que carrega.

Talvez por se imaginar (uma vez mais, retomamos a questão proposta por Pêcheux: "quem sou eu para lhe falar assim?") menos como professor e mais como criativo, ele restringe suas aulas a relatos de vivências no mercado, exposição de cases, exemplos de peças publicitárias premiadas. Com isso, em favor da tendência a reproduzir aquilo que foi feito no mercado publicitário, corre-se o risco de abrir mão das tarefas de ensino e aprendizagem, de enxergar a sala de aula como o espaço da experimentação.

Por sua vez, aqueles que ensinam sem terem exercido a profıssão ${ }^{4}$ sentem-se fragilizados

4 - Para Paulo Tarsitano, diretor do curso de Publicidade e Propaganda da Universidade Metodista, "muitos jovens acabam encontrando no magistério uma oportunidade de trabalho e passam a ensinar sem mesmo terem exercido a profissão" (CENP, 2011, p. 16). 
(mesmo que isso ocorra apenas no plano imaginário) e imaginam suprir tal fraqueza valendo-se de dinâmicas e estratégias que incluam o mundo do trabalho publicitário, como palestras com profıssionais, criação de campanhas publicitárias para clientes reais, briefings reais. 0 imaginário de que o professor se autoafirma com aquilo que faz (ou imagina que faz) fora da sala de aula gera consequências nos procedimentos didático-pedagógicos, incidindo na definição do conteúdo programático, na metodologia a ser trabalhada, nas aulas expositivas, nas atividades práticas, no plano de ensino, enfim, na prática docente e discente.

Não podemos ignorar o fato de nossa coleta de dados ter acontecido na Escola Superior de Propaganda e Marketing (ESPM). Acreditamos que a imagem que docentes e discentes fazem da ESPM - como escola de negócios e a partir do lema ensina quem faz - interfere no processo de ensino e aprendizagem de criação publicitária. Poderíamos acrescentar, de imediato, que a maneira imaginada pelo professor para se sentir pertencente e incorporar a filosofia da instituição é abranger no discurso pedagógico o discurso do mercado publicitário. Ou seja, o olhar sobre a instituição onde o professor atua é outra formulação imaginária a intervir no funcionamento do discurso pedagógico de criação publicitária.

Assim, a busca de respaldo para seu dizer no mercado e em sua vivência não docente pode estar afetada pela imagem que o professor faz da instituição de ensino em que atua. No caso da ESPM, com ligações claras com o mercado desde seu nascimento, a presença em sala de aula de profissionais atuantes ganha contornos de doutrina. "A ESPM vem desempenhando essa função de manter sua produção do conhecimento em sintonia com o mercado muito bem e há muito anos", ressalta Richard Lucht (2011, p. 44), diretor da ESPM Sul.

A filosofia de contemplar em seu quadro docente profissionais atuantes no mercado é valorizada pelo próprio mercado, conforme assinalam Paulo Tarsitano e André Porto Alegre (CENP, 2011). Ambos apontam a ausência de profissionais atuantes em sala de aula como um dos maiores problemas no ensino da publicidade e da propaganda.

Entendemos que a imagem que o professor faz de si ("quem sou eu para lhe falar assim?”) está imbricada com uma série de outras formulações imaginárias, a saber: a imagem que o professor faz da instituição de ensino superior onde leciona; o imaginário sobre o lugar de professor e o lugar de profissional de criação; a imagem da atividade acadêmica e da atividade publicitária; e, logicamente, a imagem sobre os discentes (o estudante) da ESPM.

\section{O estudante e seu lugar de interlocutor}

Recuperamos a proposição de Pêcheux (1993) sobre o lugar que A e B se atribuem para novamente deslocá-la ao ensino de criação publicitária. B, que diz respeito aos estudantes, exerce papel primordial no processo de ensino e aprendizagem e, por consequência, na geração do discurso pedagógico, já que o dizer do professor (A) passa a ser projetado em torno dele (de B). Em síntese, o estudante é o interlocutor com quem o professor se relaciona. É o outro necessariamente presente no discurso pedagógico. Por conseguinte, ressoam uma vez mais as formações imaginárias, agora com outra das questões propostas por Pêcheux (1993, p. 82): “Quem é ele para que eu lhe fale assim?". Em nosso estudo, tal questão remete à materialização da imagem que o professor atribui ao estudante, isto é, ao estudante imaginado pelo professor de disciplinas da área de criação publicitária.

As sequências discursivas (SDs) coletadas no trabalho de campo e selecionadas para análise revelam uma imagem homogeneizante dos estudantes. Levando em conta que muitos discentes da ESPM estão inseridos no mercado de trabalho, depreendemos, por intermédio da SD3, que o professor parte da premissa de que todos estão na mesma situação. Logicamente, essa premissa não é real. É fruto do imaginário 
do professor, da ordem do inconsciente. 0 professor possui a ilusão de estar contemplando a todos os estudantes em seu discurso.

SD3 - Vocês, como profissionais, têm que estar muito alinhados com isso.

É evidente que o professor, que tem contato direto com os estudantes em sala de aula, sabe que o nível de informação e conhecimento não é o mesmo em uma turma com, em média, 25 alunos. Porém, nem sempre há tempo suficiente, em um semestre e com um grupo numeroso de alunos, para conhecê-los em profundidade e muito menos para atendê-los individualmente.

Nessa mesma SD3, verificamos o tratamento dispensado aos estudantes. A projeção de uma imagem homogênea faz com que o professor precipite um conhecimento prévio dos estudantes em relação ao mercado publicitário. Em decorrência, eles são muito mais do que estudantes. São tidos como profissionais, o que não deixa de lhes ser um elogio. Há nisso, porém, um perigo ao processo de ensino e aprendizagem, se considerarmos que o grau de instrução de um profissional, em tese, é superior ao de um estudante. Todavia, os profissionais sempre têm, sim, o que aprender, mas em medida inferior aos estudantes. Grave seria se o professor, instado por essa formulação imaginária (SD3) e, por extensão, pelo clima de profissionalismo em sala de aula, relevasse conteúdos essenciais à formação estudantil.

Pedro Cappeletti, vice-presidente de criação da Fischer + Fala!, sustenta que os estudantes precisam pensar como estudantes, e não como profissionais: "os alunos estão na condição de poder errar sem medo", argumenta em entrevista ao Blog da Escola de Criação ESPM (PIFFERO, 2009).

$\mathrm{Na}$ contramão do pensamento de Cappeletti, deparamo-nos, na SD4, com a instauração, em sala de aula, da linguagem e da lógica do mundo do trabalho. Ato contínuo, a homogeneização em relação aos estudantes se intensifica. A imagem que o professor faz dos estudantes é: eles sabem o que é brainstorm; ${ }^{5}$ eles já participaram de um brainstorm; eles já produziram uma ideia brilhante; logo, são profıssionais.

SD4 - Sabe quando a gente tem no brain uma ideia muito legal [...]?

No imaginário do professor, não cabe a resposta não à sua suposição exposta na SD4, a ponto de ele partir de um tom afirmativo, e não da negação. A projeção homogênea (e ilusória) de um estudante único não permite que o professor se dê conta de que algum estudante pode erguer a mão e dizer: "não, professor, eu não sei quando a gente tem no brain uma ideia muito legal". Com certeza, essa formulação imaginária do professor tem consequência no processo de ensino e aprendizagem. Ou aceitaremos que os estudantes não se sentirão constrangidos em esboçar reação e dizer perante a classe que não sabem? Nesse caso, identificamos uma lacuna na aprendizagem, fruto de um tratamento uniforme destinado a um grupo de estudantes em detrimento do estudante como sujeito heterogêneo ${ }^{6}$ em sua caracterização, mas que é tratado homogeneamente.

Embora homogeneizante, reconhecemos que essa imagem é parte do processo de ensino e aprendizagem de criação publicitária, pois as formações imaginárias são integrantes das condições de produção que constituirão o discurso, produzindo efeitos de sentido diversos. Parece-nos evidente que a imagem que o professor faz do estudante intervém de diferentes maneiras no ensino de criação publicitária, o que demonstra uma preocupação do professor com a construção do efeito-aluno, embora, na maioria das vezes, ele projete uma imagem homogênea.

0 professor que agora nos lê deve estar confuso: de um lado, não se pode tratar todos os estudantes como profissionais, e é preciso

\footnotetext{
5 - "Prática em que o redator e o diretor de arte lançam ideias livremente para depois aperfeiçoá-las" (CARRASCOZA, 2008, p. 23).

6- Apesar de estar em segundo plano, não podemos perder de vista a pluralidade de sujeitos presentes em sala de aula. Cada estudante é um sujeito diferente. E a classe é um lugar de diversidade e pluralismo. Não podemos olhar para um grupo de estudante como se todos fossem exatamente iguais.
} 
ir mais devagar ao abordar o mercado publicitário, porque nem todos os estudantes têm o conhecimento prévio; de outro, abordar o mercado publicitário em aula é insosso, pois é repetitivo para outra camada representativa de estudantes. Mas, então, o que fazer com aqueles que não têm esse conhecimento prévio?

Em nosso modo de ver, uma vez que a turma não é uniforme, justifica-se a homogeneização, na medida em que ela é um recurso do professor diante do desafio do ensino e da aprendizagem. Ela pode ser explicada pela noção de antecipação, uma vez que o professor configura conteúdos e saberes pedagogizados a partir da antecipação de sua aceitação junto aos alunos. No momento da preparação de aula, o professor não possui contato direto com o aluno. A relação se viabiliza por meio do imaginário ("quem é ele para que eu lhe fale assim?"). É pela antecipação que ele constrói o efeito-aluno, constitutivo dos sentidos de seu dizer. 0 professor homogeneiza para poder antecipar e, consequentemente, para criar seu argumento, para organizar seu discurso. Logo, a necessidade de antecipar os efeitos do dizer implica a homogeneização do interlocutor, isto é, a antecipação depende da homogeneização.

\section{A noção de antecipação e sua aplicação no ensino de criação publicitária}

Aqui convém recordar Pêcheux e sua especulação de que todo processo discursivo supunha uma antecipação (um imaginário) das representações dos interlocutores, sobre a qual se funda a estratégia do discurso. Esta nossa análise a respeito do discurso pedagógico de criação publicitária não vai somente ao encontro do conceito de formações imaginárias, mas também se aproxima da noção complementar lançada por Pêcheux, em 1969, acerca da antecipação que o sujeito faz de seu interlocutor quanto ao sentido que suas palavras produzem, haja vista que ele dirá de uma maneira ou de outra conforme o efeito que pensa produzir em seu interlocutor.
Deslocar a noção de antecipação à prática docente equivale a afirmar que o professor (A) antecipa a repercussão de sua aula junto ao interlocutor (B). Parece-nos incontestável que a construção de sentido no discurso pedagógico é determinada pela constante inquietação que o professor tem com a imagem que o aluno faz dele, bem como com a imagem que o aluno faz das aulas, da instituição de ensino onde estuda, do mercado publicitário e do profissional de criação publicitária. Tudo isso o professor tenta antecipar para elaborar seu plano de ensino e sua metodologia de trabalho.

Assim como a pergunta "quem sou eu para lhe falar assim?" estende-se para além da imagem que o professor faz de si e funde-se com a imagem que o professor faz da instituição de ensino, do lugar de professor, do lugar de criativo, a pergunta "quem é ele para que eu lhe fale assim?" igualmente produz desdobramentos. Em síntese, o professor (A) realiza seu trabalho afetado pela incessante preocupação com os efeitos de sentido derivados de sua imagem (atribuída por B). Sustentado na imagem que cria da imagem que o estudante faz dele, o professor pode criar também as antecipações da reação do estudante acerca das aulas, dos conteúdos, do ensino, da academia, da instituição de ensino, do universo publicitário, do diretor de arte, do redator. Em razão disso, ele direcionará os procedimentos didático-pedagógicos, respingando, sem dúvida, no ensino e no aprendizado.

Para ilustrar, citamos novamente a ESPM. 0 professor antecipa que o estudante prestou vestibular e matriculou-se naquela instituição por considerá-la uma escola de referência na área de negócios e por preservar fortes vínculos com o ambiente profissional. Em decorrência, o professor antecipa que a aula a ser ministrada, para produzir efeitos de sentido, deve necessariamente contemplar o mundo do trabalho publicitário. Desse modo, ele habitua os estudantes a se confrontarem com a realidade profissional, simulando situações reais por intermédio de clientes e briefings reais, estabelecendo prazos e verbas, agendando palestras 
com profissionais de criação publicitária, entre outros procedimentos didático-pedagógicos.

Vamos adiante nesta análise. 0 professor, por antecipação e pela imagem homogênea formada acerca de seu interlocutor, julga que os estudantes querem ouvir sobre o mercado publicitário ou que precisa reportar-se a ele para capturar a atenção e despertar o interesse pela aula. Isso pode revelar-se uma armadilha, pois muitos estudantes ocupam postos no mercado de trabalho e talvez estejam fartos desse assunto em razão da prática diária, o que não significa que estejam aptos e com o aprendizado concluído.

As gravações de aula no trabalho de campo permitiram examinar a resistência e a contradição dos estudantes: por vezes, alegam que já viram, ouviram e aprenderam, no mercado de trabalho, o conteúdo exposto pelo professor, desabonando-o; porém, quando confrontados com desafios, com proposições inovadoras, preferem refugiar-se na zona de conforto, optando pelo que lhes é conhecido. Mobilizar sentidos já conhecidos e já sabidos aparenta ser mais seguro aos alunos do que se aventurar pelo ainda não sabido. Conforme lhes convêm, criticam ou elogiam a inclusão (em maior ou menor medida) de conteúdo que englobe o mercado publicitário em sala de aula, como estudos de caso, exposições e debates sobre peças e ações publicitárias premiadas, palestras com diretores de arte e/ou redatores, exercícios de criação de ideias, textos publicitários, layouts de peças e/ ou campanhas publicitárias para clientes reais.

Para tornar mais concreto o que estamos relatando, vale mencionar uma situação observada na pesquisa empírica. Da mesma maneira que os profissionais de criação que passam muito tempo enclausurados nas agências, os estudantes limitam a busca por novas referências à internet. Levando isso em conta, o professor propôs uma atividade diferente. Lançado o briefing, os estudantes, divididos em cinco grupos, deveriam ir à rua em busca de referências, novas fontes de inspiração. Poderia ser em parques, shoppings, pontos de venda, calçadas. Valia conversar com as pessoas. Não havia restrição. Enfım, poderiam ir aonde a imaginação levasse. Resultado: apenas um grupo executou a atividade. Não cabe aqui discutir a complacência do professor ou a penalização aplicada aos outros grupos. 0 que está em jogo é a imagem que o professor elaborou da turma e a que esta, por sua vez, elaborou da aula. Ademais, interessa refletir como isso repercute nas próximas aulas, via antecipação.

0 professor até pode pretender cultivar outras práticas, mas é tolhido pela resistência da turma. Nesse caso, por antecipação, precavido pela tentativa mal-sucedida, nem se aventura a experimentar o novo de novo, rendendo-se à fórmula mecânica de criação que representa praticamente um modelo único de ensino e aprendizagem, em que tudo fica padronizado, formal e procedimental. 0 risco seria chegar ao ponto que Tavares $(2010$, p. 3) denomina "pacto da mediocridade", isto é, um pacto na sala de aula, entre professor e alunos, em que ambos "ficam deslumbrados com pouco, com o comum" (GOMES, 2007, p. 160), contentando-se em meramente reproduzir o funcionamento discursivo do mercado publicitário. Atentando para o fato de a antecipação premiar um modelo padrão, ela se configuraria em um inibidor da experimentação em sala de aula, restringindo o viés laboratorial inerente ao processo de ensino-aprendizagem.

Mais um componente se acrescenta à noção de antecipação no ensino de criação publicitária. 0 professor, além de sua experiência em sala de aula e em outras disciplinas, normalmente é informado por colegas professores, pela direção do curso ou da faculdade, sobre o eco encontrado por enunciações anteriores nos estudantes e modifica paulatinamente suas pressuposições.

Desse modo, notamos o peso que o interlocutor (em especial, o estudante) tem sobre a decisão (inconsciente e ideológica) do professor em descartar alguns conteúdos e saberes pedagogizados e depositar esperanças em outros durante a preparação do curso e também no transcorrer das aulas. Aferimos que a antecipação que o professor faz do estudante quanto 
ao sentido que suas palavras produzem define se ele conduzirá sua aula de uma maneira ou de outra, conforme o efeito de sentido que pensa produzir no estudante.

Nesse sentido, lançar mão dos saberes do mundo do trabalho publicitário para conduzir as aulas parte de, no mínino, duas antecipações do professor, além daquelas já apresentadas até este instante. A primeira consiste em alcançar o respeito dos estudantes que estão inseridos no mundo publicitário, os quais são tidos, por vezes, como líderes da turma e formadores de opinião, dado o conhecimento obtido na prática publicitária. No imaginário do professor, é preponderante conquistar a confiança do estudante enquadrado nas características descritas e tê-lo ao seu lado, a seu favor e, por conseguinte, a favor do processo de ensino e aprendizagem.

Apropriar-se do dizer do mercado publicitário, deslocando-o ao ambiente acadêmico, origina no professor a ilusão de proximidade e laços de cumplicidade junto ao estudante. Ao trabalhar com as prováveis expectativas estudantis, com aspirações muitas vezes não verbalizadas, o professor ancora sua aula no discurso do universo profissional com a finalidade de ser simpático, de seduzir e - por que não? - de ser bem avaliado.

0 efeito de antecipação da recepção, da percepção e da aceitação do discurso pedagógico de criação publicitária em relação aos estudantes que desempenham atividades profissionais prolonga-se àqueles que ainda não conquistaram ou não procuraram seu espaço no mercado de trabalho. Justamente por essa razão acontece o segundo caso de antecipação por nós aventado, em que o professor transfere elementos do discurso do mercado publicitário. Como os estudantes ainda não atuam profissionalmente, o docente prevê sua narrativa sobre o mercado publicitário como novidade. Eis uma formulação imaginária superada.

0 estudante atual está muito mais informado do que o do passado. Nossos alunos estão cercados por informação. Livros, periódicos, sites especializados, redes sociais, entre tantos outros meios e plataformas, reproduzem a rotina do mercado publicitário e abastecem os estudantes com informações. Hoje, mais do que nunca, eles chegam à universidade com uma grande carga informativa. Tal fenômeno, em vez de fazer com que o aluno seja penalizado por não prestar atenção, deveria gerar uma mudança na prática pedagógica. As instituições de ensino e os professores precisam entender essa nova condição.

Para um dos pesquisadores mais respeitados nos Estados Unidos, o venezuelano Fernando Reimers (2011), professor de Educação Internacional e diretor do Programa de Políticas Educacionais Internacionais da Universidade de Harvard, o bombardeio de informações liberta os melhores professores para assumirem a função que muitos deles sempre quiseram: a de envolver as mentes de seus alunos para trabalhar em parceria com eles, discutindo ideias complexas e desafios e encontrando maneiras de resolvê-los. Na opinião de Reimers (2011), em um mundo no qual os estudantes podem ter acesso instantâneo a informações sobre fatos e dados no telefone celular ou na internet, faria pouco sentido os professores passarem a maior parte do tempo transmitindo isso a eles.

Como vimos, a estratégia discursiva da antecipação prevê a possibilidade de respostas e dirige a argumentação. Dito diferentemente, o conteúdo a ser ensinado e os procedimentos didático-pedagógicos só são definidos a partir das formulações imaginárias construídas. Na verdade, a movimentação dos sentidos no discurso pedagógico de criação publicitária apenas toma corpo diante da participação imaginária do aluno. A antecipação do efeito de sentido que o dizer do professor (A) evocará no estudante (B) estabelecerá o modo como o mercado publicitário será empregado no fazer educativo.

De acordo com Orlandi (1993), o sujeito antecipa-se a seu interlocutor quanto ao sentido que suas palavras produzem, o que vai regular a argumentação do discurso, já que o sujeito dirá de um modo ou de outro segundo o efeito que pensa produzir em seu ouvinte. Observamos, assim, a importância dos efeitos 
das antecipações de imagens entre os interlocutores na constituição do sentido de um discurso, já que elas direcionarão as posições que locutor e interlocutor ocuparão nesse discurso.

\section{Considerações finais}

Toda a reflexão produzida ao longo deste artigo pode e deve ser canalizada para iluminar a prática do ensino de criação publicitária. Com isso, não queremos dizer que as práticas já consagradas devem ser postas de lado. Mas entendemos que se o professor souber que não há uma única forma de ensinar, isso já pode afetar, e muito, a qualidade de seu ensino de criação publicitária.

Pelo percurso aqui realizado, observamos o discurso pedagógico de criação publicitária permeado pelo discurso do mercado publicitário. Nas gravações das aulas no trabalho de campo, identificamos como a projeção do professor sobre o próprio lugar e sobre o lugar de seu interlocutor impacta o entrelaçamento entre o discurso pedagógico e o discurso profissional.

Está nítida a força que o imaginário sobre o outro (seja ele o mercado publicitário, os colegas professores, a instituição de ensino ou, em especial, o estudante) exerce na definição dos conteúdos programáticos e dos procedimentos didático-pedagógicos do professor. Mostramos de que maneira as formulações imaginárias intervêm no funcionamento do discurso pedagógico de criação publicitária e determinam o modo como o mercado publicitário é incluído no fazer educativo. A equação assim se materializa: o estudante chega como determinação para os saberes pedagogizados em sala de aula; em decorrência do estudante imaginado, o mercado publicitário chega como determinação para o discurso pedagógico de criação publicitária.

Indo um pouco além, não estamos pregando que se deixe o mercado à margem. Ao contrário. Mas estamos dizendo que é possível deslizar de uma reprodução de informação para uma produção de conhecimento (BACCEGA, 2004) a fim de que os estudantes aprendam melhor. 0 espaço da sala de aula e os sujeitos nele envolvidos não precisam conformar-se com um processo de ensino e aprendizagem procedimental, linear e rotineiro. Diríamos que pelo menos isso já seria alentador e o resultado poderia ainda suscitar novas reflexões sobre práticas pedagógicas.

Algumas vezes, embora isoladas, o professor experimenta outras práticas. Porém, é paralisado pela antecipação da resistência de todo um sistema de ensino, formado pelas instituições, pelos professores, pelos estudantes, pelo mercado publicitário. As representações socialmente incorporadas, como o lugar de professor e o lugar de aluno, são exploradas pelo professor na concepção de seu dizer, afetando decisivamente a prática em sala de aula e a ação educativa.

Por fim, as formulações imaginárias que rondam a cabeça do professor - a imagem que ele atribui a si e aos estudantes - levam-no a inserir o discurso do mundo do trabalho publicitário em sala de aula, produzindo implicações no processo de ensino e aprendizagem de criação publicitária. A antecipação que o professor (A) faz dos efeitos de sentido despertados no estudante (B) dá luz à aula, ao conteúdo programático escolhido, à maneira de ministrá-lo e, consequentemente, à decisão por abordar (ou não) o mercado publicitário. Em outros termos, o imaginário do professor (A) sobre o aluno (B) rege a preparação e a condução da aula. Por isso ele recorre ao mercado publicitário.

Em suma, as formações imaginárias fazem parte das condições de produção do discurso pedagógico de criação publicitária e impõem-se como indispensáveis ao fazer educativo. Tal constatação comprova que os sentidos são produzidos em decorrência de um mecanismo imaginário, parte necessária do funcionamento da linguagem. Por meio desse jogo, as palavras refletem sentidos imaginados ou possíveis. 


\section{Referências}

BACCEGA, Maria Aparecida. Comunicação/educação: apontamentos para discussão. Comunicação, Mídia e Consumo, São Paulo, v. 1, n. 2, p. 119-138, nov. 2004.

CARRASCOZA, João Anzanello. Do caos à criação publicitária: processo criativo, plágio e ready-made na publicidade. São Paulo: Saraiva, 2008.

CENP (Conselho Executivo das Normas-Padrão). Mamãe: quero ser publicitário. CENP em Revista, São Paulo, ano 7, n. 28, p. 16-17, set. 2011.

FERREIRA, Jorge Carlos Felz. Reflexões sobre o ser professor: a construção de um professor intelectual. [s. d.]. Disponível em: <http://www.bocc.uff.br/pag/felz-jorge-reflexoes-sobre-ser-professor.pdf>. Acesso em: 15 jul. 2010.

GOMES, Neusa Demartini. Pensando o ensino de publicidade e propaganda: contribuições da academia e do mercado para uma melhor sintonia. In: KUNSCH, Margarida M. Krohling (Org.). Ensino de comunicação: qualidade na formação acadêmicoprofissional. São Paulo: ECA-USP: Intercom, 2007. p. 153-165.

HANSEN, Fábio. 0 ensino de criação publicitária e sua relação com o mercado publicitário. In: CONGRESSO BRASILEIRO DE CIÊNCIAS DA COMUNICAÇÃO, 34., 2011, Recife. Anais... Recife, 2011a. (XI Encontro dos Grupos de Pesquisa em Comunicação, DT 2 - Publicidade e Propaganda, GP - Epistemologia e Linguagem).

. Relaç̃aes de consumo entre o mercado publicitário e o ensino e a aprendizagem de criação publicitária. In: CONGRESSO INTERNACIONAL EM COMUNICAÇÃO E PRÁTICAS DE CONSUMO, 1., 2011, São Paulo. Anais..., São Paulo, 2011b.

HANSEN, Fábio; NEUMANN, Anna Laura; SILVA, Taíssi Alessandra Cardoso da. 0 atravessamento do mercado publicitário no ensino da publicidade: uma análise discursiva. In: CONGRESSO BRASILEIRO DE CIÊNCIAS DA COMUNICAÇÃO, 33., 2010, Caxias do Sul. Anais..., Caxias do Sul, 2010. (X Encontro dos Grupos de Pesquisa em Comunicação, DT 2 - Publicidade e Propaganda, GP Epistemologia e Linguagem).

LUCHT, Richard. Região se destaca pela qualidade do ensino de comunicação. Meio \& Mensagem Especial: Região Sul, São Paulo, p. 43-45, 5 dez. 2011.

ORLANDI, Eni. Discurso e leitura. 2. ed. São Paulo: Cortez; Campinas: Unicamp, 1993.

PÊCHEUX, Michel. Análise automática do discurso. Tradução de Eni Orlandi. In: GADET, Françoise; HAK, Tony (Orgs.). Por uma análise automática do discurso: uma introdução à obra de Michel Pêcheux. 2 ed. Campinas: Unicamp, 1993. p. 61-161.

PIFFERO, Luiza. Cappeletti: "Pense como estudante, não como profissional”. 21 out. 2009. Disponível em: <http://escoladecriacao. espm.br/2009/pense-como-estudante-nao-como-profissional/>. Acesso em: 10 mar. 2012.

REIMERS, Fernando. As escolas perdem tempo ensinando habilidades que foram úteis no passado. Carta Escola, São Paulo, ano 26. n. 243, p. 32-34, jun./jul. 2011.

TAVARES, Dirceu. Conceito de interatividade no ensino da publicidade. In: CONGRESSO BRASILEIRO DE CIÊNCIAS DA COMUNICAÇÃO, 33., 2010, Caxias do Sul. Anais..., Caxias do Sul, 2010. (X Encontro dos Grupos de Pesquisa em Comunicação, DT 2 - Publicidade e Propaganda, GP - Epistemologia e Linguagem).

Recebido em: 05.05.2012

Aprovado em: 14.11.2012

Fábio Hansen é publicitário, doutor em Letras pela Universidade Federal do Rio Grande do Sul (UFRGS) e mestre em Educação, Administração e Comunicação. Atualmente, é professor na Escola Superior de Propaganda e Marketing Sul (ESPM Sul), onde coordena a área de pesquisa. É pesquisador do Grupo de Estudo em Educação Superior e a Formação do Sujeito. 